OPEN ACCESS

Edited by:

Boris C. Rodríguez-Martín,

Proyecto PlaniFive, Spain

Reviewed by:

Marzia Del Zotto

Médecins Sans

Frontières, Switzerland

Alexandra Wolf,

Kyushu University, Japan

*Correspondence: Joao C. Hiluy

jhiluy@gmail.com

Specialty section: This article was submitted to Eating Behavior, a section of the journal

Frontiers in Psychology

Received: 21 October 2020 Accepted: 29 March 2021

Published: 29 April 2021

Citation:

Hiluy JC, David IA, Daquer AFC,

Duchesne M, Volchan E and Appolinario JC (2021) A Systematic

Review of Electrophysiological

Findings in Binge-Purge Eating

Disorders: A Window Into Brain Dynamics. Front. Psychol. 12:619780.

doi: 10.3389/fpsyg.2021.619780

\section{A Systematic Review of Electrophysiological Findings in Binge-Purge Eating Disorders: A Window Into Brain Dynamics}

\author{
Joao C. Hiluy ${ }^{1 *}$, Isabel A. David ${ }^{2}$, Adriana F. C. Daquer ${ }^{1,3}$, Monica Duchesne ${ }^{1,3}$, \\ Eliane Volchan ${ }^{4}$ and Jose C. Appolinario ${ }^{1,3}$ \\ ${ }^{1}$ Obesity and Eating Disorders Group, Institute of Psychiatry, Federal University of Rio de Janeiro, Rio de Janeiro, Brazil, \\ ${ }^{2}$ Laboratory of Behavioral Neurophysiology, Physiology and Pharmacology Department, Biomedical Institute, Federal \\ Fluminense University, Niteroi, Brazil, ${ }^{3}$ State Institute of Diabetes and Endocrinology, Rio de Janeiro, Brazil, ${ }^{4}$ Carlos Chagas \\ Filho Institute of Biophysics, Federal University of Rio de Janeiro, Rio de Janeiro, Brazil
}

Binge-purge eating disorders (BP-ED), such as bulimia nervosa and binge eating disorder, may share some neurobiological features. Electroencephalography (EEG) is a non-invasive measurement modality that may aid in research and diagnosis of BP-ED. We conducted a systematic review of the literature on EEG findings in BP-ED, seeking to summarize and analyze the current evidence, as well as identify shortcomings and gaps to inform new perspectives for future studies. Following PRISMA Statement recommendations, the PubMed, Embase, and Web of Science databases were searched using terms related to "electroencephalography" and "binge-purge" eating disorders. Of 555 articles retrieved, 15 met predefined inclusion criteria and were included for full-text analysis. Eleven studies investigated EEG by means of event-related potentials (ERP) in BP-ED individuals: 7 using eating disorder-related stimuli (i.e., food, body image) and 4 using non-eating disorder-related stimuli (i.e., facial expressions or auditory clicks). These studies found significant differences in the N200, P200, P300, and LPP components in BP-ED participants compared to controls, indicating that this population exhibits impairments in selective attention, attentional allocation/processing, and allocation of motivational or emotion-based attention. Five studies investigated EEG using frequency analysis; reporting significant differences in beta activity in fronto-temporal and occipito-temporo-parietal areas in BP-ED individuals compared to controls, revealing a dysfunctional brain network. However, the small number of studies, the heterogeneity of samples, study paradigms, stimulus types, and the lack of an adequate assessment of neuropsychological parameters are some limitations of the current literature. Although some EEG data are promising and consistent with neuroimaging and neuropsychological findings in individuals with BP-ED, future studies need to overcome current methodological shortcomings.

Keywords: EEG, binge eating, neurophysiology, bulimia nervosa, electroneurophysiology, ERP, frequency analysis 


\section{INTRODUCTION}

Eating disorders are characterized by a persistent disturbance of eating or eating-related behavior that results in the altered consumption or absorption of food, with a significant impact on physical health or psychosocial functioning (American Psychiatric Association, 2013). Although the eating disorders field has witnessed significant development in the last decades, there is scant information about the pathophysiology of these conditions. A better understanding of the neurophysiology of eating disorders is crucial for improvement in diagnosis and treatment, and still represents a great challenge for clinicians and researchers (Fairburn and Harrison, 2003; Jansen, 2016). Studies of neuroimaging, neuropsychological assessments, and genetic investigation have been performed to elucidate the pathophysiology of EDs. In line with the recommendations of the Research Domain Criteria framework (Insel et al., 2010; U. S. Department of Health Human Services, 2020), some research has begun to look for possible neurobiological markers of eatingdisordered behaviors.

According to the main diagnostic classifications (the Diagnostic and Statistical Manual of Mental Disorders, DSM, and the International Classification of Diseases, ICD), the ED group is divided into several categories, with anorexia nervosa $(\mathrm{AN})$, bulimia nervosa $(\mathrm{BN})$, and binge eating disorder (BED) as the three major diagnostic rubrics. However, there is a growing body of evidence suggesting an alternative, dimensional classification based on distinct clinical and neurobiological characteristics (Brooks et al., 2012). Specifically, authors hypothesized that ED could be described as a continuum, with disorders characterized by restriction and appetite control (AN) on one pole and, at the opposite pole, disorders characterized by loss of control and increased appetite (BN and BED) (Fairburn and Harrison, 2003). The restricted-type EDs are associated with such cognitive disturbances as perfectionism, cognitive rigidity, problems with change of focus and excessive attention to detail, ruminations, and obsessions about feeding and worries with body weight (Tchanturia et al., 2002, 2004; Startup et al., 2013; Kułakowska et al., 2014). On the other hand, the impulsivetype EDs (which include $\mathrm{BN}$ and $\mathrm{BED}$ ) are characterized by impulsiveness, high excitability, borderline personality traits, and a higher rate of substance abuse (Verkes et al., 1996; Krug et al., 2009; Monica et al., 2010; Pearson et al., 2017).

Some neurobiological findings have been described in this subgroup of binge-purge eating disorders (BP-ED). For instance, functional magnetic resonance imaging (fMRI) studies have shown that individuals with BED exhibit increased activity in the medial orbitofrontal cortex, a reward-processing area of the brain, in response to images of high-calorie foods (Schienle et al., 2009). Additionally, other neuroimaging methods, as well as neuropsychological assessments, have suggested that BP-ED is

\footnotetext{
Abbreviations: AN, Anorexia nervosa; BN, Bulimia Nervosa; BED, Binge eating disorder; BP-ED, Binge-Purge Eating Disorders; ED, Eating disorder; EEG, Electroencephalography; EPN, Early posterior negativity; ERN, Error related negativity; ERP, Event-Related Potentials; LPP, Late positive potential; SPW, Slow positive wave.
}

associated with altered function in cortical and striatal regions, increased attentional shifting to foods, an increase in aspects related to the desire for food, and a decreased sensitivity to reward (Kessler et al., 2016).

Current evidence suggests that the attention domain is particularly relevant in the cognitive processes of individuals with BP-ED; individuals in this subgroup exhibit specific attentional bias (Stojek et al., 2018). For example, in 2016, Albery et al. used an emotional-Stroop task to measure attentional biases in individuals with BN (Albery et al., 2016). They found a cognitive bias for food and body-related cues in individuals with $\mathrm{BN}$, but not in controls. Likewise, Leehr et al. compared the valuation of food vs. non-food stimuli by overweight subjects with $\mathrm{BED}$, overweight subjects without $\mathrm{BED}$, and normal-weight controls and found that the BED group showed a significantly stronger food bias compared to non-BED overweight subjects (Leehr et al., 2016). Preliminary evidence suggests that attentional bias to disorder-specific stimulus (such as food or weigh/shape cues) may be a potent contributor to the development and maintenance of binge eating.

An interesting method to assess the underlying brain physiology is electroencephalography (EEG), a low-cost technique with excellent temporal resolution that consists of recording the electrical activity produced by cortical neurons in the brain through electrodes placed on the scalp (Niedermeyer and da Silva, 2004). Several analyses can be applied to the EEG signal, of which two are commonly used for studying neuroelectrophysiological parameters: time domain analysis and frequency domain analysis.

Time domain analysis (event-related potential, ERP) assesses the systematic positive or negative voltage deflections (electrical brain waves) that occur in response to repeated stimuli or motor events (Luck, 2014; Kessler et al., 2016). Study of ERPs allows recording of the time course of cortical processes of related events in a time-locked manner with a specific stimulus. ERPs are typically distinguished by their time window of occurrence, morphology, topography on the scalp, and response to experimental manipulations (Luck, 2014). ERP waveforms may be associated with motor, cognitive, or sensory functions, and are described according to the type of task and stimuli used during the study, their distribution on the scalp (topography), amplitude, polarity, and latency (Kessler et al., 2016). Early ERP waveforms, occurring 0-200 ms after stimulus onset, are termed sensory or exogenous, as they are largely modulated by the physical aspects of the presented stimuli (e.g., color, brightness, spatial frequency, complexity). In contrast, ERP waveforms that occur at later time windows after stimulus presentation are termed endogenous, as they are determined less by the physical features of the stimulus and more by the reactions of the subject in response to the stimulus or a task. For example, endogenous generated components of P300 and later components (e.g., N400) are sensitive indicators of selective attention and semantic processing in response to a task (Cohen, 2014; Herrmann et al., 2014). As timing is an important factor in the allocation of attentional resources to food stimuli (Wolz et al., 2015), and temporal aspects of this attentional allocation can be measured by ERPs, it is important that ERP measures be employed to improve 
our knowledge of the differential allocation of attention to food or body shape stimuli in patients with BP-ED. ERP studies are also useful to elucidate potential perceptual, motor, motivational, and emotional impairments linked to BP-ED. A summary of outcome measures of the main ERPs is presented in Table $\mathbf{1}$.

Additionally, EEG signals can be decomposed into frequencies (e.g., alpha, beta, theta, delta) to look for condition-related oscillatory patterns (Luck, 2014; Kim and Im, 2018). Neural oscillations and their synchronization may provide useful insights into interneuronal communication and integration of neural information that is processed in distributed brain regions (Kim and Im, 2018). This spectral analysis of the EEG enables digital representation of the aforementioned frequency bands (Andreassi, 2010). Changes in specific bands may be an indicator of increased firing rate within certain cell populations, reflecting different stages of cognitive arousal, cognitive processing, and psychopathology (Klimesch, 1999; Makeig et al., 2004). In summary, frequency analysis can additionally provide helpful information to clarify the relationship between brain functions, cognitive functions, and eating behavior. An overview of frequency bands and associated cognitive states is presented in Table 2.

In 2012, Lobera et al. conducted the first-ever review of the cerebral electrophysiology of ED (Jáuregui-Lobera, 2012), focusing on studies which explored EEG findings of sleep/resting states in patients with AN. Only three studies included samples with patients with binge eating (Rodriguez et al., 2007; Tammela et al., 2010; Blechert et al., 2011a). Of these, two used frequencydomain EEG analysis (Rodriguez et al., 2007; Tammela et al., 2010), whereas the third applied time-domain (ERP) analysis (Blechert et al., 2011a). Two findings regarding EEG in BP-ED individuals emerged from this review: obese individuals with binge eating showed greater frontal beta activity when compared to those without binge eating, and individuals with $\mathrm{BN}$ exhibited affective priming compared with healthy controls. Another review was conducted in 2015 by Wolz et al. (2015). Although not focused on patients with binge-eating spectrum disorders, it did include two studies of patients presenting episodes of binge eating, one with a BN sample (Blechert et al., 2011b) and another with BED subjects (Svaldi et al., 2010). This review focused on ERP findings and did not include any studies using frequency-domain EEG analysis. More recently, two reviews of electrophysiological findings in ED were published. The first, conducted in 2018, investigated abnormalities in the EEG power spectrum in individuals with BN, BED, and obesity (Blume et al., 2019). Of seven studies included (Léonard et al., 1998; Tammela et al., 2010; Hume et al., 2015a,b; Imperatori et al., 2015; Bauer and Manning, 2016; Wolz et al., 2017), only four assessed BN or BED (Léonard et al., 1998; Tammela et al., 2010; Imperatori et al., 2015; Wolz et al., 2017); the other three evaluated obesity alone (Hume et al., 2015a,b; Bauer and Manning, 2016). The authors found that (1) beta activity on resting-state EEG was elevated in fronto-central regions in individuals with obesity and comorbid BED; and (2) beta activity correlated positively with ED psychopathology at rest and following exposure to food cues.

The most recent review was performed in 2019 and focused on ERP in response to food stimuli among individuals with ED and weight disorders (Chami et al., 2019). The authors found that individuals with binge eating exhibited an enhanced attentional response to food cues compared to healthy controls. They also reported that inhibitory control-related ERP components (N200 and P300a) increased during food-specific exposure but did not differentiate overweight from normal-weight groups.

In summary, the current literature provides preliminary evidence of the potential usefulness of electrophysiological methods to assess cerebral function in patients with ED. However, the inclusion of multiple diagnostic rubrics in the same reviews is a common limitation. As EDs are a heterogeneous group, it is important to understand that they are expected to present with different neurobiological features captured by EEG. We conducted this systematic review to collate and analyze the current evidence on EEG findings (including ERP and frequency analyses), in the more homogeneous spectrum of BP-ED. We also aimed to identify additional limitations of the current research to inform futures directions in the field. We seek to provide an overview of current knowledge regarding the electrophysiology of BP-ED, applying different analyses to gain new insights into the pathophysiological processes underlying sensory, cognitive, and affective deficits as well as clinical symptoms in these disorders.

\section{METHODS}

\section{Literature Search}

Two authors (JCH and ACD) independently conducted a systematic search of the PubMed, Embase, and Web of Science databases from inception through July 1, 2020, using the following terms: ("binge-eating disorder" or "bulimia" or "abnormal eating") and ("electroencephalography" or "electroencephalogram" or "EEG" or "brain waves" or "evoked potentials" or "event-related potential”). No filters for date of publication were applied. The electronic search strategy was supplemented by a handsearch for additional articles in the reference lists of included articles and previous reviews. This review adheres to the PRISMA reporting guidelines (Moher et al., 2009).

\section{Inclusion and Exclusion Criteria}

Original articles that performed an EEG method in individuals with BP-ED were included. Cross-sectional or longitudinal studies were required to describe EEG neurophysiological outcome data. The BP-ED diagnosis should be confirmed by a validated assessment instrument based on an international classification system (DSM or ICD). Case studies, articles evaluating sleep EEG, samples composed of children, and reviews were excluded, although their reference lists were screened for additional articles not retrieved in the initial search.

\section{Data Extraction}

Two authors (JCH and ACD) independently screened and selected the studies based on titles and abstracts. After consensus on the first round of selection, both authors independently reviewed the full text of the selected studies to determine their suitability for inclusion, based on the established selection criteria. Disagreements between the two authors were solved by 
TABLE 1 | ERP components by time latency and functional significance.

\begin{tabular}{|c|c|c|}
\hline ERP & $\begin{array}{l}\text { Time latency after } \\
\text { stimulus onset (ms) }\end{array}$ & Functional significance \\
\hline $\begin{array}{l}\text { N100 } \\
\text { (or N1) }\end{array}$ & 90-200 & $\begin{array}{l}\text { Early sensory processing and automatic orienting (Hillyard et al., 1998; Vogel and Luck, 2000; David } \\
\text { et al., 2011; Kappenman and Luck, 2011) }\end{array}$ \\
\hline $\begin{array}{l}\text { Error related } \\
\text { negativity (ERN) }\end{array}$ & $80-150$ & Individual error processing (Gehring et al., 2011, 2018; Wang et al., 2020) \\
\hline $\begin{array}{l}\text { P200 } \\
\text { (or P2) }\end{array}$ & $100-250$ & $\begin{array}{l}\text { Early selective attention } \\
\text { Attentional and cognitive processing } \\
\text { Automatic orienting to stimuli (Crowley and Colrain, 2004; Pacheco et al., 2020) }\end{array}$ \\
\hline $\begin{array}{l}\text { N200 } \\
\text { (or N2) }\end{array}$ & 180-300 & $\begin{array}{l}\text { Conflict detection during the regulation of successful behavior (Donkers and van Boxtel, 2004; } \\
\text { Folstein and Van Petten, 2007; Riesel et al., 2017; Heidlmayr et al., 2020) }\end{array}$ \\
\hline $\begin{array}{l}\text { Early posterior } \\
\text { negativity (EPN) }\end{array}$ & 200-300 & $\begin{array}{l}\text { Valence processing } \\
\text { Stimulus arousal } \\
\text { Attention allocation (Junghofer et al., 2001; Schupp et al., 2003a,b, 2007; Farkas et al., 2020; } \\
\text { Hajcak and Foti, 2020; Lemos et al., 2020) }\end{array}$ \\
\hline N400 (or N4) & $250-500$ & Processes indexing access to semantic memory (Kutas and Federmeier, 2011) \\
\hline $\begin{array}{l}\text { Late positive } \\
\text { potential (LPP) }\end{array}$ & $300-1,000$ & $\begin{array}{l}\text { Conscious allocation of attention } \\
\text { Allocation of motivational or emotion-based attention (Hajcak et al., 2010; Brown et al., 2012; } \\
\text { Hajcak and Foti, 2020) }\end{array}$ \\
\hline $\begin{array}{l}\text { Slow positive } \\
\text { wave (SPW) }\end{array}$ & $500-6,000$ & Categorization and response selection processes (Johnston et al., 1986; daSilva et al., 2016) \\
\hline
\end{tabular}

TABLE 2 | Frequency bands and associated cognitive states.

\begin{tabular}{lll}
\hline Frequency & Band $\mathbf{( H z )}$ & Functional significance \\
\hline Delta & $1-4$ & Sleep state \\
Theta & $4-8$ & Arrhythmic delta connected to problem-solving tasks (Niedermeyer and da Silva, 2004) \\
& Wakefulness with state of forced attention \\
& Creativity \\
& Distractibility \\
& Inattention (Niedermeyer and da Silva, 2004) \\
Alpha & Relaxed wakefulness \\
& & Meditation \\
Beta & Peacefulness (Niedermeyer and da Silva, 2004) \\
& Attentive wakefulness \\
& Focus \\
& Relaxed thinking (Niedermeyer and da Silva, 2004) \\
\end{tabular}

discussion with each other and with the senior author (JCA) until consensus was reached. One author (JCH) extracted data from each study using a form designed for the purpose of the present review. Data of interest included sample size, diagnosis, stimulus type, task performed, measures, primary outcome, and main findings.

\section{Quality Assessment}

Our quality assessment tool included seven questions from the original Newcastle-Ottawa Quality Assessment Scale adapted for cross sectional studies (Herzog et al., 2013), as well as three additional questions regarding EEG quality: (1) "does the author report specific hypotheses and predictions for the EEG measures in the introduction?", (2) "was the description of EEG data preprocessing steps clear and detailed?", and (3) "were the stimuli standardized and paired by characteristics?" Our assessment ranged from 0 (minimum) to 10 (maximum).

\section{RESULTS}

The initial search identified 555 potentially eligible articles. After removal of duplicates, 464 studies remained. Screening of titles and abstracts reduced this to 42 studies, which were assessed for eligibility. After full-text reading, 27 studies were excluded for a variety of reasons (Figure 1). The final sample thus consisted of 15 articles.

Below, we describe the findings of the included articles. Individual sections are provided for time-domain and frequencydomain analyses. It is important to note that although, a few 


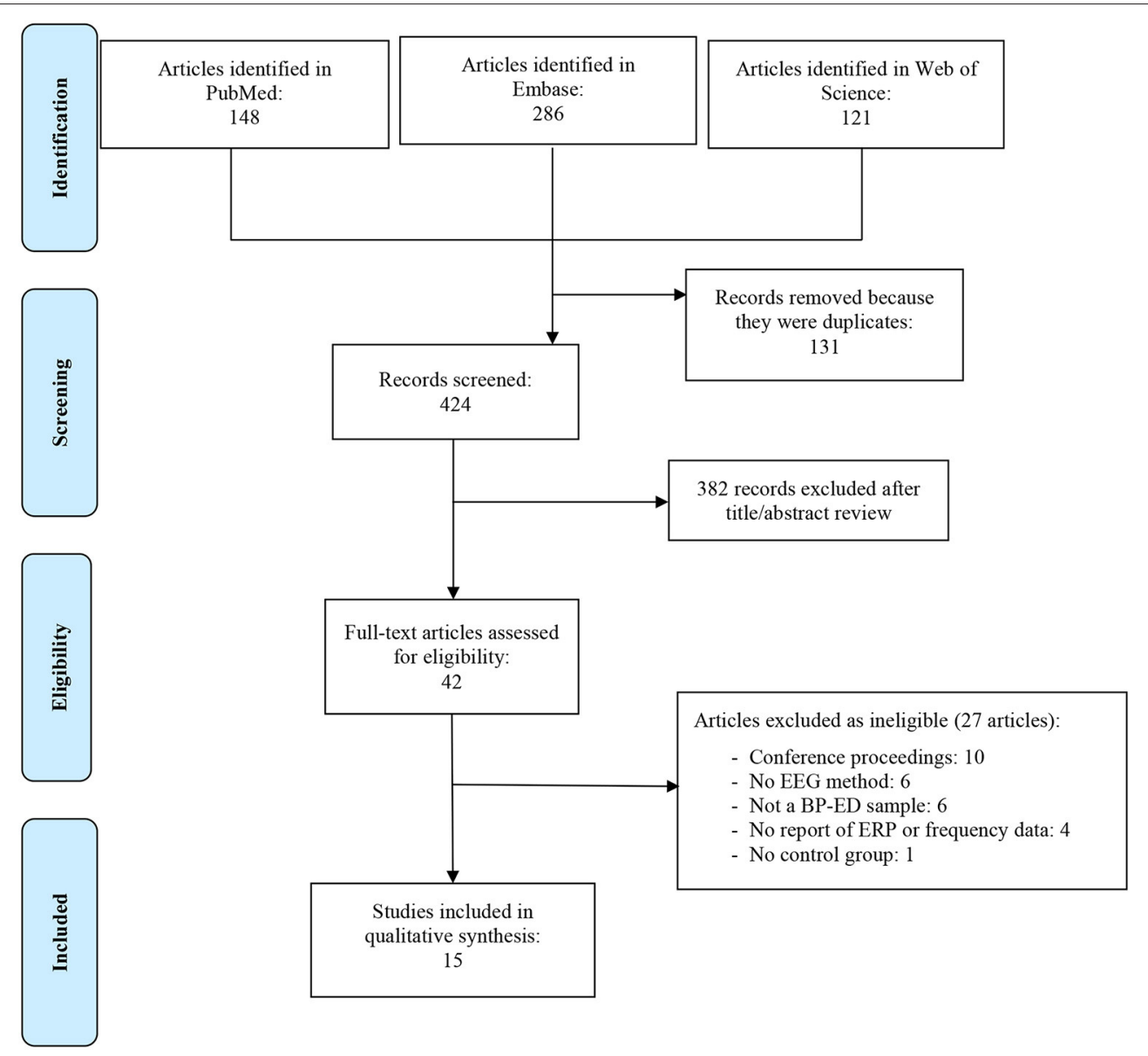

FIGURE 1 | PRISMA flow diagram.

studies included a subsample of participants with $\mathrm{AN}$, we excluded these data from our discussion.

\section{Time-Domain Analysis (ERP)}

We found a total of 11 studies investigating central markers by means of ERP in individuals with BP-EDs (Table 3). These studies employed different stimuli to evoke ERPs in two categories: (1) non-eating disorder-related stimuli, i.e., those not related to ED psychopathology (auditory clicks or facial images, for example); and (2) stimuli related to ED psychopathology (food pictures or body-related images).

\section{Non-eating Disorder-Related Stimuli}

The first study evaluating ERP in BP-ED individuals was performed in 1997 (Otagaki et al., 1998). The authors hypothesized that, as individuals with ED exhibit some cognitive impairments (McKay et al., 1986; Jones et al., 1991) and the P300 component reflects cognitive function in the brain (Sutton et al., 1965), this ERP could be a psychobiologic marker of eating disordered behaviors. They used a two-tone discrimination task - the oddball paradigm - to assess P300 in $24 \mathrm{BN}$ individuals compared with 40 healthy controls. The oddball paradigm consists of the discrimination of an infrequent sequence or stimulus (the target stimulus) among frequent (nontarget) stimuli and is commonly used to assess P300. The BN participants had a significant prolonged P300 latency compared to those in the control group. The authors suggest that this result may reflect that individuals with $\mathrm{BN}$ may present a task-related slowing of cognitive processing.

Using another non-eating disorder-related stimulus, Kuehnpast et al. (2012) performed an ERP study in individuals with BP-ED. These authors presented images of facial expressions (neutral, happy, fearful, and angry) to 13 participants with $\mathrm{BN}$ and 13 healthy controls. Several ERPs were analyzed: N170, N200, and P300. Compared to healthy controls, the BN group showed (1) a reduced N170 amplitude for angry faces; (2) a higher P300 mean amplitude independent of facial expression; and (3) a higher amplitude for distractor stimuli (P300a) and target stimuli (P300b). These results demonstrated that emotional faces can be processed differently in persons with $\mathrm{BN}$. In conclusion, individuals with $\mathrm{BN}$ failed to allocate more attentional resources to motivationally relevant stimuli, which demonstrates that early cortical decoding processes might not be functional. To compensate for this failure, these individuals 
TABLE 3 | Time domain analysis: studies evaluating ERP waveforms in BP-ED.

\begin{tabular}{|c|c|c|c|c|c|}
\hline References & $\begin{array}{l}\text { Sample }(n) \\
\text { diagnostic }\end{array}$ & Stimulus & Measures & ERP & Main findings \\
\hline \multicolumn{6}{|c|}{ Non-eating disorder related Stimuli } \\
\hline $\begin{array}{l}\text { Otagaki et al. } \\
\text { (1998) }\end{array}$ & $\begin{array}{c}\mathrm{AN}=28 \mathrm{BN}=24 \mathrm{HC}=40 \\
(\mathrm{DSM}-\mathrm{IV})\end{array}$ & $\begin{array}{l}\text { Two-tone } \\
\text { discrimination task } \\
\text { ("oddball" } \\
\text { paradigm) }\end{array}$ & $\begin{array}{l}\text { EAT-26; SDS; STAI; } \\
\text { BIS-10 }\end{array}$ & $\begin{array}{l}\mathrm{P} 300 \\
250-450 \mathrm{~ms}\end{array}$ & $\mathrm{BN}$ group exhibited a prolonged latency compared to $\mathrm{HC}$ \\
\hline \multirow[t]{5}{*}{$\begin{array}{l}\text { Kuehnpast et al. } \\
\text { (2012) }\end{array}$} & $\begin{array}{l}\mathrm{BN}=13 \mathrm{HC}=13 \\
\quad(\mathrm{DSM}-\mathrm{II} / \mathrm{IV})\end{array}$ & $\begin{array}{l}\text { Neutral, happy, fearful, } \\
\text { and angry facial } \\
\text { expressions }\end{array}$ & SCID & $\begin{array}{l}\mathrm{N} 170 \\
120-180 \mathrm{~ms}\end{array}$ & $\begin{array}{l}\text { BN group: reduced amplitudes for angry faces compared to } \\
\mathrm{HC}\end{array}$ \\
\hline & & & & $\begin{array}{l}\text { N2 } \\
190-260 \mathrm{~ms}\end{array}$ & $\begin{array}{l}\text { Higher scores in depression were associated with more } \\
\text { negative N200 amplitudes }\end{array}$ \\
\hline & & & & $\begin{array}{l}\mathrm{P} 300 \\
270-500 \mathrm{~ms}\end{array}$ & $\begin{array}{l}\text { BN group: Higher mean amplitudes compared with } \mathrm{HC} \\
\text { independent of emotional expression }\end{array}$ \\
\hline & & & & $\begin{array}{l}\text { P300 } \\
300-650 \mathrm{~ms}\end{array}$ & $\begin{array}{l}\text { BN group: Higher amplitude for distractor stimuli (P300a) and } \\
\text { for targets (P300b) }\end{array}$ \\
\hline & & & & $\begin{array}{l}\text { SW } \\
350-800 \mathrm{~ms}\end{array}$ & $\begin{array}{l}\text { BN group: Increased amplitude and shorter latency } \\
\text { compared to HC }\end{array}$ \\
\hline $\begin{array}{l}\text { Merlotti et al. } \\
\text { (2013) }\end{array}$ & $\begin{array}{l}\mathrm{BN}=17 \mathrm{HC}=17 \\
\quad(\mathrm{DSM}-\mathrm{IV}-\mathrm{TR})\end{array}$ & $\begin{array}{l}\text { Three-tone auditory } \\
\text { oddball paradigm }\end{array}$ & $\begin{array}{l}\text { ERP; SCID-I; BIS-11; } \\
\text { EDI-2; BITE; WAIS-R }\end{array}$ & $\begin{array}{l}\text { N2 } \\
200-350 m s\end{array}$ & $\begin{array}{l}\text { BN group: Reduced amplitude and shorter latency compared } \\
\text { to } \mathrm{HC}\end{array}$ \\
\hline $\begin{array}{l}\text { Blechert et al. } \\
\text { (2011a) }\end{array}$ & $\begin{array}{c}\mathrm{AN}=20 \mathrm{BN}=20 \mathrm{HC}=28 \\
(\mathrm{DSM}-\mathrm{IV})\end{array}$ & $\begin{array}{l}\text { Sentences eliciting } \\
\text { body shape, weight, } \\
\text { and typical eating } \\
\text { concerns of ED } \\
\text { patients }\end{array}$ & $\begin{array}{l}\text { ERP; EDE; EDE-Q; } \\
\text { BDI; RSE; MSES; SCID }\end{array}$ & $\begin{array}{l}\mathrm{N} 400 \\
340-450 \mathrm{~ms}\end{array}$ & $\begin{array}{l}\text { BN group: Amplitudes higher (more negative) for incongruent } \\
\text { conditions }\end{array}$ \\
\hline \multicolumn{6}{|l|}{ Food Stimuli } \\
\hline \multirow[t]{2}{*}{ Svaldi et al. (2010) } & $\begin{array}{l}\mathrm{BED}=22 \\
\mathrm{GC}=22 \\
(\mathrm{DSM}-\mathrm{IV}-\mathrm{TR})\end{array}$ & $\begin{array}{l}\text { Food pictures (high- } \\
\text { and low-calorie). }\end{array}$ & ERP; EDE; DEBQ & $\begin{array}{l}\text { LPP } \\
500-800 \mathrm{~ms}\end{array}$ & $\begin{array}{l}\text { BED group: Increased for high-calorie food pictures } \\
\text { compared to GC. } \\
\text { No differences between groups on low-calorie food pictures. }\end{array}$ \\
\hline & & & & $\begin{array}{l}\text { SPW } \\
1000- \\
6000 \mathrm{~ms}\end{array}$ & $\begin{array}{l}\text { BED group: Larger amplitudes compared to GC. } \\
\text { BED group: Larger with high-calorie food pictures compared } \\
\text { to GC. } \\
\text { No significant group difference in response to low-calorie } \\
\text { food pictures. }\end{array}$ \\
\hline $\begin{array}{l}\text { Blechert et al. } \\
\text { (2011b) }\end{array}$ & $\begin{array}{l}\mathrm{BN}=22 \\
\mathrm{AN}=21 \\
\mathrm{HC}=32 \\
(\mathrm{DSM}-\mathrm{IV})\end{array}$ & $\begin{array}{l}\text { Food (high- and } \\
\text { low-calorie) vs. } \\
\text { non-food related } \\
\text { images. }\end{array}$ & $\begin{array}{l}\text { ERP; EDE; EDE-Q; } \\
\text { STAI; BDI }\end{array}$ & $\begin{array}{l}\text { EPN } \\
220-310 \mathrm{~ms}\end{array}$ & $\begin{array}{l}\text { BN group: Higher for food pictures compared with neutral. } \\
\text { No difference between high- and low-calorie categories. }\end{array}$ \\
\hline \multirow[t]{2}{*}{$\begin{array}{l}\text { Schienle et al. } \\
\text { (2017) }\end{array}$} & $\begin{array}{c}E G=36 \\
\text { (19 BED and } 17 \text { BED low } \\
\text { frequency) } \\
\text { HC }=38 \\
(\mathrm{DSM}-5)\end{array}$ & $\begin{array}{l}\text { Food pictures (high- } \\
\text { and low-calorie). } \\
\text { Two groups: bitter or } \\
\text { water condition }\end{array}$ & EDI; QADP; BAS & $\begin{array}{l}\text { P200 } \\
150-200 \mathrm{~ms}\end{array}$ & $\begin{array}{l}\text { EG: Higher in both food picture categories in bitter condition } \\
\text { compared with HC. }\end{array}$ \\
\hline & & & & $\begin{array}{l}\text { LPP } \\
400-700 \mathrm{~ms}\end{array}$ & $\begin{array}{l}\text { EG: higher in both food categories in the bitter condition } \\
\text { compared with HC. }\end{array}$ \\
\hline
\end{tabular}


TABLE 3 | Continued

\begin{tabular}{|c|c|c|c|c|c|}
\hline References & $\begin{array}{l}\text { Sample }(n) \\
\text { diagnostic }\end{array}$ & Stimulus & Measures & ERP & Main findings \\
\hline \multirow[t]{2}{*}{ Wolz et al. (2017) } & $\begin{array}{l}\mathrm{EG}=19 \\
(\mathrm{BN}=12 \\
\mathrm{BED}=7) \\
\mathrm{HC}=20 \\
(\mathrm{DSM}-5)\end{array}$ & $\begin{array}{l}\text { Chocolate odor and } \\
\text { pictures }\end{array}$ & $\begin{array}{l}\text { FCCQ; DERS; YFAS; } \\
\text { EDI-2; SCL-90-R }\end{array}$ & $\begin{array}{l}\text { N2 } \\
180-350 \mathrm{~ms}\end{array}$ & $\begin{array}{l}\text { EG: higher amplitudes for chocolate pictures primed by } \\
\text { chocolate odor compared to neutral odor. }\end{array}$ \\
\hline & & & & $\begin{array}{l}\text { LPP } \\
300-1000 \mathrm{~ms}\end{array}$ & No differences between $\mathrm{HC}$ and EG. \\
\hline \multirow[t]{2}{*}{ Leehr et al. (2018) } & $\begin{array}{c}\text { OW+BED } \\
(n=24) \\
\text { OW-BED } \\
(n=23) \\
\text { NWC } \\
(n=26) \\
(\mathrm{DSM}-\mathrm{IV})\end{array}$ & $\begin{array}{l}\text { High-calorie food } \\
\text { pictures and non-food } \\
\text { pictures }\end{array}$ & BDI-II ASTS & $\begin{array}{l}\text { N2 } \\
150-250 \mathrm{~ms}\end{array}$ & $\begin{array}{l}\text { Latencies were significantly larger in OW without BED } \\
\text { compared with OW+BED individuals and NWC sample }\end{array}$ \\
\hline & & & & $\begin{array}{l}\text { ERN } \\
0-150 m s\end{array}$ & No differences in latencies and amplitudes \\
\hline \multirow[t]{2}{*}{$\begin{array}{l}\text { Delgado- } \\
\text { Rodríguez et al. } \\
\text { (2019) }\end{array}$} & $\begin{array}{r}\mathrm{BN}=24 \\
\mathrm{HC}=24 \\
(\mathrm{DSM}-5)\end{array}$ & $\begin{array}{l}\text { Images of high-calorie } \\
\text { foods, erotic couples, } \\
\text { neutral objects, and } \\
\text { unpleasant scenes }\end{array}$ & $\begin{array}{l}\text { EAT; BITE; BDI; FCQ-t; } \\
\text { FCQ-s; SHAPS; STAI }\end{array}$ & $\begin{array}{l}\text { EPN } \\
220-310 \mathrm{~ms}\end{array}$ & No differences in latencies and amplitudes \\
\hline & & & & $\begin{array}{l}\text { LPP } \\
500-800 \mathrm{~ms}\end{array}$ & $\begin{array}{l}\text { BN group exhibited a larger amplitude with binge food and } \\
\text { erotic cues }\end{array}$ \\
\hline \multicolumn{6}{|l|}{ Body/shape stimuli } \\
\hline \multirow[t]{5}{*}{ Mai et al. (2015) } & $\begin{array}{l}\mathrm{BN}=20 \mathrm{HC}=20 \\
\quad(\mathrm{DSM}-\mathrm{IV})\end{array}$ & $\begin{array}{l}\text { Body-related images } \\
\text { (underweight, normal, } \\
\text { and overweight) }\end{array}$ & $\begin{array}{l}\text { ERP; SCID-I; RS; STAI; } \\
\text { BDI-II; EDI-2 }\end{array}$ & $\begin{array}{l}\text { N170 } \\
150-220 \mathrm{~ms}\end{array}$ & $\begin{array}{l}\text { No significant main or interaction effects on amplitude or } \\
\text { latency }\end{array}$ \\
\hline & & & & $\begin{array}{l}\text { P200 } \\
180-270 \mathrm{~ms}\end{array}$ & $\begin{array}{l}\text { Both groups: Lowest amplitudes for underweight body stimuli } \\
\text { compared to normal body stimuli } \\
\text { BN group: Higher amplitude in response to overweight stimuli } \\
\text { compared to normal body stimuli }\end{array}$ \\
\hline & & & & $\begin{array}{l}\text { N2 } \\
250-350 \mathrm{~ms}\end{array}$ & $\begin{array}{l}\text { Both groups: Most pronounced amplitudes for underweight } \\
\text { compared to normal and overweight body stimuli Only HC } \\
\text { exhibited more negative N200 in response to underweight } \\
\text { compared to normal and overweight body stimuli HC group: } \\
\text { Significantly shorter latency compared to BN }\end{array}$ \\
\hline & & & & $\begin{array}{l}\text { P3 } \\
350-450 \mathrm{~ms}\end{array}$ & $\begin{array}{l}\text { HC group: Higher amplitudes compared to BN to overweight } \\
\text { and normal-body stimuli }\end{array}$ \\
\hline & & & & $\begin{array}{l}\text { SW } \\
500-900 m s\end{array}$ & $\begin{array}{l}\text { More positive for underweight body stimuli compared to } \\
\text { overweight and normal. No differences between BN and HC }\end{array}$ \\
\hline
\end{tabular}

ASTS, State Mood Scale; BAS, Behavioral Activation Scale; BDI, Beck Depression Inventory; BES, Binge Eating Scale; BIS-10, Barratt Impulsiveness Scale 10; BIS-11, Barratt Impulsiveness Scale 11; BITE, Bulimic Investigation Test Edinburgh; CG, control group; DEBQ, Dutch Eating Behavior Questionnaire; DERS, Difficulties in Emotion Regulation Scale; EAT, Eating Attitude Test; EAT-26, Eating Attitude Test 26; EDE, Eating Disorder Examination; EDE-Q, Eating Disorder Examination Questionnaire; EDI, Eating Disorder Inventory; EDI-2, Eating Disorder Inventory-2; FCCQ, Food Chocolate-Craving Questionnaire; FCQ-s, Food Craving Questionnaire (state); FCQ-t, Food Craving Questionnaire (traits); HADS, Hospital Anxiety and Depression Scale; HC, healthy control; OW, overweight; MSES, Multidimensional Self Esteem Scale; NR, not reported; QADP, Questionnaire for the Assessment of Disgust Proneness; RS, Restraint Scale; RSE, Rosenberg Self-Esteem Scale; SCID, Structured Clinical Interview for DSM; SCL-90-R, Symptom Checklist-90 Revised; SHAPS, Snaith-Hamilton Pleasure Scale; SDS, Zung's Self-Rating Depression Scale; STAl, State-Trait Anxiety Inventory; TAS, Toronto Alexithymia Scale; TFEQ, Three-Factor Eating Questionnaire; WAIS-R, Wechsler Adult Intelligence Scale - revised; YFAS, Yale Food Addiction Scale. 
devote a higher amount of cognitive effort to evaluating facial expressions.

In 2013, Merlotti et al. (2013) conducted another ERP study using a three-tone auditory oddball paradigm in a group of $17 \mathrm{BN}$ participants compared to a healthy control group ( $n$ $=17$ ). This procedure is a variant of the oddball paradigm which has the possible advantage of allowing assessment of other cognitive processes than those obtained in the traditional paradigm (Wronka et al., 2008). The authors found a reduced amplitude and shorter latency in $\mathrm{N} 200$ in the $\mathrm{BN}$ group compared to healthy controls. In addition, they reported an association between impulsivity (measured by the Barratt Impulsivity Scale) and the reduction in N200 latency. Authors also reported an increased amplitude and short latency of the target slow wave (SW) and a higher amplitude of the P300 component. Taking together, these observations suggest the occurrence of functional abnormalities in brain activities involved in attention and selfregulatory control (such as a deficit in the inhibitory processes and an excessive allocation of attentive resources to irrelevant stimuli), possibly related to impulsivity in BN.

In summary, the ERP studies using non-eating disorderrelated stimuli suggest that individuals with BP-ED may exhibit impaired cognitive processing independently of stimulus characteristics. These alterations may be associated with the attentional deficits observed in this group of individuals.

\section{Eating Disorder-Related Stimuli}

The first study using food stimuli to assess ERP in BP-ED was performed by Svaldi et al. (2010). The authors compared 22 BED participants with 22 overweight subjects (control group) and assessed late positive potential (LPP) and slow positive wave (SPW) after presenting images of high-calorie and lowcalorie foods. The experiment consisted of two sections. In a "viewing section," participants simply viewed food pictures, while in the "availability section," participants were instructed to taste some foods during the sequence. An increased amplitude of LPP and SPW for high-calorie food pictures was observed in the BED group compared to controls. Of note, the differences were greater during the "availability section" of the experiment. In conclusion, for women with BED, high-calorie foods may have high motivational properties and attract high levels of attentional resources in information processing.

Blechert et al. (2011b) evaluated EPN in a subsequent study with a sample composed by $22 \mathrm{BN}$ participants and 32 healthy controls. They used a set of high- and low-calorie food pictures, compared with non-food-related images. A higher EPN for both high- and low-calorie food pictures compared to neutral pictures was found in BN group (no difference between highand low-calorie categories). In healthy controls, EPN were higher only for high-calorie food pictures (with no difference between neutral pictures and those of low-calorie foods). In this study, participants with BN showed a generalized attentional bias for food images, regardless of caloric value. A relevant limitation of this study is that, although the authors used non-food images from the International Affective Picture System (IAPS) as control stimuli, they did not describe the source of the food pictures displayed.
In 2017, Schienle et al. (2017) performed a study using a taste perception paradigm to check if a bitter test (in which the perception of bitterness usually reduces the salience of the food cues presented) could change the reward value of visual food cues. They assessed the ERP components P200 and LPP in a sample of 36 BED participants compared to 38 healthy control individuals. Pictures of high- and low-calorie foods were used to evoke ERP potentials. In this study, the BED group displayed a higher P200 amplitude for both high- and low-calorie food pictures compared to healthy controls in the bitter condition. The BED group also showed higher LPP for both food images during the bitter condition when compared to the control group. Hence, results showed that exposure to a bitter taste did not decrease the late-positive ERP component to visual food cues (reflecting food reward sensitivity) in women with BED. The authors suggested that this atypical bitter response (as bitter taste reduced P200/LPP to food images in healthy women) might be a biological marker of BED and, possibly, related to overeating in these individuals.

Another study was performed by Wolz et al. (2017) in a sample of 12 subjects with $\mathrm{BN}, 7$ subjects with BED, and 20 healthy controls. The authors conducted a clinical experiment using a combination of visual and olfactory chocolate stimuli to assess N200 and LPP. Although chocolate pictures elicited a higher LPP than neutral images, there was no significant difference between the experimental group and controls in N200 and LPP amplitudes. The authors concluded that BP-ED might be associated with lower baseline N200 activity and a higher relative increase in response to chocolate cues than healthy controls, and argued that the lack of significance may have been due to the small sample size or to the olfactory stimulus serving as a confounding factor.

Leehr et al. (2018) performed a study using food-related stimuli in BP-ED individuals to assess N200 and error-related negativity (ERN) in three groups: (I) overweight patients with BED, (II) overweight individuals without BED, and (III) normal-weight controls, using high-calorie food pictures and neutral images. The results showed that N200 latencies were significantly larger in the non-BED compared with BED group. This prolonged N200 latency is related to conflict processing and could be attributed to a compensatory mechanism. Subsequently, the authors concluded that, as the BED group did not exhibit this larger N200 latency, they did not intensify conflict monitoring processes, failing to overcome potential deficits in inhibitory control.

More recently, Delgado-Rodríguez et al. (2019) conducted an ERP study to evaluate the LPP response to food and erotic cues in individuals with $\mathrm{BN}$. The authors hypothesized that as these individuals exhibit aversion to body cues, the motivational significance of erotic images could be increased in women with BN. This study compared the LPP response of 24 women with BN to that of 24 healthy controls. A significant larger LPP amplitude was found in the bulimic group in response to pictures of binge-related foods and erotic pictures. The findings suggest the importance of LPP as an indicator of motivational significance activity of cortical and subcortical areas involved in emotional perception, as LPP is not affected by perceptual characteristics of the stimulus as early ERP components used to be. Thus, the LPP 
component may be a pathway to assess altered processing food cues and eating disorder-related stimuli in $\mathrm{BN}$.

The first study to investigate electrophysiological parameters in response to body image stimuli in subjects with BP-ED was performed by Mai et al. (2015). In this experiment, the authors assessed the N170, P200, N200, P300, and SW components in a sample of 40 participants (20 with $\mathrm{BN}$ and 20 matched healthy controls). The task consisted of the presentation of underweight, normal, and overweight body pictures; participants were instructed to evaluate these images in terms of their reactions (pleasantness and arousal). This study showed that BN subjects exhibited a greater P200 amplitude in response to overweight stimuli compared to normal-body pictures. Regarding N200, healthy controls presented a more negative amplitude in response to underweight body stimuli when compared to normal and overweight body stimuli. In addition, healthy controls exhibited higher P300 amplitudes for overweight and normal-body stimuli compared to the BN group. No differences were found in N170 and SW between groups. Participants with $\mathrm{BN}$ also rated overweight body stimuli as bigger and more arousing, highlighting that overweight bodies provoke altered perceptual and cognitive-affective processing. The authors confirmed their hypothesis that individuals with $\mathrm{BN}$ exhibit alterations in the processing of female body stimuli in response to underweight, normal-weight, and overweight body images.

Although not using pictures, Blechert et al. (2011a) conducted another ERP study with eating disorder-related stimuli in 2010. In this study, 20 participants with $\mathrm{BN}$ and 28 healthy controls were included. The authors used sentences eliciting body shape, weight, and typical eating concerns of eating-disordered patients to assess N400. Overall, when compared to participants with $\mathrm{BN}$, healthy controls showed higher N400 amplitudes (more negative) for incongruent conditions (e.g., "when I gain weight, I feel... accepted"). The results suggested that the neural affective processing of individuals with $\mathrm{BN}$ indicated a tighter link between self-evaluation domains and shape/weight concerns as compared to the other groups.

In summary, ERP investigations using eating disorder-related stimuli confirm the findings raised by studies with noneating disorder-related stimuli in individuals with BP-ED. These subjects displayed a range of impairments from early sensory processing and selective attention through to late cognitive processes, conscious allocation of attention, and allocation of motivational or emotion-based attention.

\section{Frequency Domain Analysis}

A total of five studies focused specifically on frequency-band changes in EEG-measured brain activity in BP-ED samples were retrieved (Table 4). In general, early studies were composed of mixed samples (usually with AN), while more recent studies selected more homogenous samples.

The first study assessing frequency-band changes in the EEG in BP-ED populations was performed in 1998 by Léonard et al. (1998). In their study, the sample was composed of 14 participants with $\mathrm{AN}, 10$ with $\mathrm{BN}$, and 18 healthy controls. The authors performed a resting-state EEG followed by a "meal session" in which EEG was recorded before, during, and after a meal. They assessed alpha, beta, delta, and theta frequency bands, but did not find any statistically significant differences between groups.

The second investigation was performed by Rodriguez et al. 9 years later (Rodriguez et al., 2007). The authors evaluated alpha, delta, and theta frequency bands on resting-state EEG in a sample composed of three groups: AN $(n=16)$, BN $(n=12)$, and healthy controls $(n=30)$. They hypothesized that, as EDs might be related to distortion of body image, a topographical evaluation of cortical rhythmicity might reveal EEG abnormalities. In their study, the alpha power amplitude in central, parietal, occipital, limbic, and temporal electrodes was lower in patients with $\mathrm{BN}$ compared to healthy controls, especially in posterior regions represented by the temporal, parietal, and occipital lobes. Contradicting their hypothesis, no differences in delta and theta frequencies were found between groups. The authors concluded that participants with $\mathrm{BN}$ showed to altered mechanisms of cortical neural synchronization, especially in Rolandic alpha rhythms. As this study included $\mathrm{AN}$ and $\mathrm{BN}$ samples, is not clear which findings could be related to binge episodes, precluding any conclusions regarding BP-ED neural synchronization.

After these two initial studies, in 2010 Tammela et al. (2010) performed a resting-state EEG investigation using food stimuli in a sample composed of 12 obese participants with bingeeating episodes and 13 obese participants without such episodes. Higher frontal beta activity was found in the experimental group, independently of the stimulus used. The disinhibition factor of the Three-Factor Eating Questionnaire (TFEQ) correlated positively with this increased beta activity. The authors reported no significant differences in amplitudes in alpha, delta, or theta frequencies. The authors proposed that elevated frontal beta activity could be a marker of a dysfunctional disinhibitioninhibition mechanism (Tammela et al., 2010) in those individuals. It is important to point out that the authors did not assess BED categorically; instead, they used the high cutoff point of the Binge Rating Scale $(B E S \geq 27)$ to define a group of binge eaters.

Another EEG frequency-domain analysis study was performed by Imperatori et al. (2015). The authors assessed beta frequency in a resting-state EEG with eyes closed in obese or overweight patients with $\operatorname{BED}(n=13)$ and obese or overweight patients without $\operatorname{BED}(n=13)$. The EEG functional connectivity showed that the BED group demonstrated an increase in lagged-phase synchronization in the beta frequency in a network involving frontal, temporal, and occipital areas, compared to patients without BED. The authors suggested that this neurophysiological pattern may reflect a hyper-excitability of the frontal control and visual processing networks, which lead BED individuals to be more vulnerable to food cues and exhibit a higher lack of control overeating.

The last study in this section, performed in 2017 by Wolz et al. analyzed theta frequency in $12 \mathrm{BN}$ participants (seven BED and 20 healthy controls) during an event-related brain response experiment to access the influence of olfactory and visual stimuli on craving, inhibitory control, and motivated attention. The authors found no significant difference in frontal theta frequency between groups (Wolz et al., 2017). 
TABLE 4 | Frequency domain analysis: studies evaluating EEG oscillatory activity in BP-ED.

\begin{tabular}{|c|c|c|c|c|c|c|}
\hline References & Sample (n) diagnostic & Stimulus/Task & Measures & $\begin{array}{l}\text { Frequency } \\
\text { band }\end{array}$ & Main findings & Comments \\
\hline $\begin{array}{l}\text { Léonard et al. } \\
\text { (1998) }\end{array}$ & $\begin{array}{l}\mathrm{AN}=14 \\
\mathrm{BN}=10 \\
\mathrm{HC}=18 \\
(\mathrm{DSM}-\mathrm{IV})\end{array}$ & $\begin{array}{l}\text { Before meal (resting } \\
\text { state) and meal (on } \\
\text { starting, during and } \\
\text { after the end of the } \\
\text { meal) }\end{array}$ & EDI; HADS; STAI & $\begin{array}{l}\text { Alpha, beta, } \\
\text { delta, and } \\
\text { theta }\end{array}$ & $\begin{array}{l}\text { No significant differences } \\
\text { between groups }\end{array}$ & $\begin{array}{l}\text { First study to assess EEG data in patients } \\
\text { with eating disorders }\end{array}$ \\
\hline \multirow[t]{3}{*}{$\begin{array}{l}\text { Rodriguez et al. } \\
\text { (2007) }\end{array}$} & $\begin{array}{l}\mathrm{AN}=16 \\
\mathrm{BN}=12 \\
\mathrm{HC}=30 \\
\text { (DSM IV-TR) }\end{array}$ & $\begin{array}{l}\text { Resting-state EEG } \\
\text { (eyes closed) }\end{array}$ & $N R$ & Alpha 1 & $\begin{array}{l}\text { HC exhibited increased } \\
\text { amplitude compared with BN in } \\
\text { temporal, central, parietal, } \\
\text { occipital, and limbic sites }\end{array}$ & $\begin{array}{l}\text { Alpha } 1 \text { amplitude in central sites was } \\
\text { correlated with BMI in patients }\end{array}$ \\
\hline & & & & Alpha 2 & $\begin{array}{l}\mathrm{HC}>\mathrm{AN} \text { and BN (parietal, } \\
\text { occipital, and limbic) }\end{array}$ & \\
\hline & & & & $\begin{array}{l}\text { Delta and } \\
\text { theta }\end{array}$ & $\begin{array}{l}\text { No significant differences } \\
\text { between groups }\end{array}$ & \\
\hline \multirow[t]{2}{*}{$\begin{array}{l}\text { Tammela et al. } \\
\text { (2010) }\end{array}$} & $\begin{array}{c}\text { EG: } 12 \text { Obese BE } \\
\text { GC: } 13 \text { Obese without BE } \\
(B E S>26)\end{array}$ & $\begin{array}{l}\text { Resting-state EEG } \\
\text { (eyes-closed) and } \\
\text { focused (eyes-open) } \\
\text { during food stimuli }\end{array}$ & $\begin{array}{l}\text { BITE; QEWP; TFEQ; } \\
\text { DEBQ; BDI }\end{array}$ & Beta activity & $\begin{array}{l}\text { EG presented higher frontal } \\
\text { activity in all situations } \\
\text { (stimulus-independent) }\end{array}$ & $\begin{array}{l}\text { Entire sample composed of obese } \\
\text { individuals }\end{array}$ \\
\hline & & & & $\begin{array}{l}\text { Alpha, delta, } \\
\text { and theta }\end{array}$ & $\begin{array}{l}\text { No significant differences } \\
\text { between groups }\end{array}$ & \\
\hline $\begin{array}{l}\text { Imperatori et al. } \\
\text { (2015) }\end{array}$ & $\begin{array}{c}\text { EG: } 13 \text { Obese/OW with } \\
\text { BED } \\
\text { GC: } 13 \text { Obese/OW without } \\
\text { BED } \\
\text { (DSM-IV-TR) }\end{array}$ & $\begin{array}{l}\text { Resting-state EEG } \\
\text { (eyes closed) }\end{array}$ & BES; HADS & Beta & $\begin{array}{l}\text { EG: increased lagged phase } \\
\text { synchronization in } \\
\text { frontal-temporal and } \\
\text { occipito-temporo-parietal areas }\end{array}$ & $\begin{array}{l}\text { EEG connectivity values were significantly } \\
\text { related to BE, even after controlling for } \\
\text { depression symptoms }\end{array}$ \\
\hline Wolz et al. (2017) & $\begin{array}{l}E G=19 \\
(B N=12 \\
B E D=7) \\
H C=20\end{array}$ & $\begin{array}{l}\text { Chocolate odor and } \\
\text { pictures }\end{array}$ & $\begin{array}{l}\text { FCCQ; DERS; YFAS; } \\
\text { EDI-2; SCL-90-R }\end{array}$ & Theta & $\begin{array}{l}\text { No difference in frontal power } \\
\text { between groups }\end{array}$ & \\
\hline
\end{tabular}

BAS, Behavioral Activation Scale; BDI, Beck Depression Inventory; BES, Binge Eating Scale; BIS-11, Barratt Impulsiveness Scale; BITE, Bulimic Investigation Test Edinburgh; DEBQ, Dutch Eating Behavior Questionnaire; DERS, Difficulties in Emotion Regulation Scale; EDE, Eating Disorder Examination; EDE-Q, Eating Disorder Examination Questionnaire; EDI, Eating Disorder Inventory; EDI-2, Eating Disorder Inventory-2; EG, experimental group; FCCQ, Food ChocolateCraving Questionnaire; CG, control group; HADS, Hospital Anxiety and Depression Scale; HC, healthy control; OW, overweight; MSES, Multidimensional Self Esteem Scale; NR, not reported; QADP, Questionnaire for the Assessment of Disgust Proneness; RS, Restraint Scale; RSE, Rosenberg Self-Esteem Scale; SCID, Structured Clinical Interview for DSM; SCL-90-R, Symptom Checklist-90 Revised; STAl, State-Trait Anxiety Inventory; TAS, Toronto Alexithymia Scale; TFEQ, Three-Factor Eating Questionnaire; WAIS-R, Wechsler Adult Intelligence Scale - revised; YFAS, Yale Food Addiction Scale. 


\section{Quality Appraisal}

The 15 included studies scored from 5 to 9 on the modified Newcastle-Ottawa Quality Assessment Scale. Two studies (Rodriguez et al., 2007; Blechert et al., 2011a) reached scores of 5 or 6, nine studies (Léonard et al., 1998; Otagaki et al., 1998; Tammela et al., 2010; Kuehnpast et al., 2012; Merlotti et al., 2013; Mai et al., 2015; Wolz et al., 2017; Leehr et al., 2018) 7 or 8, and four studies (Blechert et al., 2011b; Imperatori et al., 2015; Schienle et al., 2017; Delgado-Rodríguez et al., 2019) scored 9. The major weaknesses found in the studies included (1) absence of sample size calculation, (2) comparability of the groups (e.g., large differences between subgroup characteristics, such as BMI) and (3) the absence of a standardized and paired stimulus used in the tasks.

\section{DISCUSSION}

Our systematic review found a total of 15 studies evaluating electrophysiologic data in individuals with BP-ED. Most articles (11) were ERP studies, while five performed EEG frequency analysis. Taken together, the results of the studies included this review point to a series of electroencephalographic changes in individuals with BP-ED. Regarding time-domain analysis, changes were found at different times after the stimulus onset. Altered initial ERPs (N200, P200, EPN), responsible for early sensory processing, attention allocation, valence processing, and cognitive/attentional processing, demonstrate an altered initial cognitive response, mainly elicited by eating disorder-related cues (food pictures, body images). In addition, changes in late ERPs (LPP and SPW) can reveal an impaired allocation of motivational attribution or emotional-based attention. Thus, these ERP changes may indicate that individuals with BPED have a different cognitive processing of stimuli. Despite fewer studies, frequency analysis investigations revealed that individuals with BP-ED exhibit specific alterations in EEG-based brain activity. The increased beta activity, predominantly in fronto-temporal and occipito-temporo-parietal areas, point to a dysfunctional brain network possibly involved in attentional focus toward food stimuli and an increased awareness and vulnerability to food cues.

It bears stressing that our findings are in line with current knowledge of the pathophysiology of BP-ED conditions (Kessler et al., 2016; Steinglass et al., 2019). After an extensive review of the literature, Kessler et al. (2016) proposed a neurobiological basis of BED based on recent neuroimaging, neurocognitive, and genetic data. Their proposal included: (i) altered function in cortical and striatal areas; and (ii) cognitive deficits in executive function, inhibitory control, attention, decision making, and mental flexibility. Another important aspect observed by the authors was the differential response of BP-ED individuals to environmental cues, particularly food-related cues. They proposed that altered cortical function contributes significantly to the altered reward sensitivity and impulsivity observed in BED individuals. Likewise, Steinglass et al. (2019) reviewed the neurobiology of $\mathrm{BN}$ and found data suggesting an increased reinforcing value of food, changes in the brain reward system in association with food, and an inhibitory control that is particularly pronounced in the context of food cues.

Some electrophysiological findings observed in the studies included in this review may be related to an overlap with symptoms observed in other mental disorders closely related to BP-EDs. Several other disorders are characterized by impulsivity and behavioral disinhibition, such as ADHD, alcoholism, and other substance use disorders (Imperatori et al., 2015). In these conditions, beta activity and beta coherence have been observed. Abnormal cortical processing along multiple time windows might be related to alterations in oscillatory EEG activity in the beta band frequency along prefrontal-visual cortical pathways. Thus, it is interesting to analyze electrophysiological data from other conditions that are frequently comorbid with ED to help elucidate possible correlates and suggest new directions for cerebral electrophysiology research on this topic. As impulsivity is an important feature of BP-ED, we examined two other conditions associated with impulsivity impairment: substance use disorders (SUD) and attentiondeficit/hyperactivity disorder (ADHD). A meta-analysis carried out by Littel et al. (2012) evaluated electrophysiological indices of biased cognitive processing in individuals with SUD. These authors found that P300 and SP (ERPs associated with attentional resources to motivationally relevant stimuli) were significantly larger in SUD participants compared with controls. In addition, SUD individuals exhibited enhanced electrophysiological processing of substance-related cues as compared to neutral cues. This can be interpreted in terms of substance users' motivated attention. In the same line, Johnstone et al. reviewed the ERP literature in ADHD over the last 10 years and found altered N200 and P300 patterns, usually preceded by differences in earlier components (N100 and P200), and in ERN and error positivity $(\mathrm{Pe})$, reflecting problems in selective attention, inhibitory control, and error-processing components. It is interesting to note that several findings presented in these SUD and ADHD studies are quite similar to those found in some BP-EDs, with which they may share some neuropsychological features (Kaisari et al., 2017).

Several limitations of the included studies should be considered. More homogeneous samples in terms of diagnosis and clinical status (illness duration, severity level) are needed. Other parameters, such as gender and clinical comorbidities, can act as confounders and should be addressed as such. In addition, studies usually assessed small samples and did not perform a priori sample size calculation, which can limit the external validity of the results. The lack of standardization in EEG paradigms hinders comparison between studies and made it impossible to perform a meta-analysis. Finally, there was a heterogeneity in the stimuli presented and the ERPs measured, with no standardization of the food pictures used across different studies.

Future cerebral electrophysiological studies are warranted in the field of ED, as it appears that EEG findings can provide particularly useful insights into ED neurobiology. We believe that forthcoming research should help clinicians understand whether the EEG changes observed in individuals with BP-ED are state or trait-related. Longitudinal studies could clarify this important 
aspect. An example of this approach was employed recently in a study conducted by Chami et al. (2020), who piloted a trial of inhibitory training involving participants with $\mathrm{BN}$ and $\mathrm{BED}$, exploring behavioral outcomes (i.e., reaction times, omission errors, and commission errors) and changes in N200 and P300 from baseline to post-intervention. Even though participants in the intervention group showed reductions in binge eating frequency, the neural processes underlying this clinical effect could not be entirely uncovered by the post-intervention EEG. The authors concluded that it still unclear whether the null findings reflect an absence of change in neural activity over time or an inability of the measures to detect change; they suggested that future research explore different task parameters.

In conclusion, altered EEG parameters are seen in individuals with BP-ED, suggesting several impairments in neural processing at different levels. Research is still incipient, and future studies need to overcome several shortcomings to confirm the utility of EEG techniques in the assessment of patients with BP-ED. If confirmed as a window to assessment of brain dynamics, EEG should help elucidate the underlying mechanisms of binge eating.

\section{DATA AVAILABILITY STATEMENT}

The original contributions presented in the study are included in the article/supplementary material, further inquiries can be directed to the corresponding author.

\section{AUTHOR CONTRIBUTIONS}

$\mathrm{JH}$ and $\mathrm{AD}$ : literature search and manuscript preparation. ID and JA: review of data and manuscript. $\mathrm{MD}$ and $\mathrm{EV}$ : review of manuscript. All authors contributed to the article and approved the submitted version.

\section{ACKNOWLEDGMENTS}

Presented as an oral presentation at the 2020 Virtual International Conference on Eating Disorders, Sydney, Australia.

\section{REFERENCES}

Albery, I. P., Wilcockson, T., Frings, D., Moss, A. C., Caselli, G., and Spada, M. M. (2016). Examining the relationship between selective attentional bias for foodand body-related stimuli and purging behaviour in bulimia nervosa. Appetite 107, 208-212. doi: 10.1016/j.appet.2016.08.006

American Psychiatric Association (2013). Diagnostic and Statistical Manual of Mental Disorders. Vol. 11, Diagnostic and Statistical Manual of Mental Disorders, 5th Edition. Washington, DC: American Psychiatric Association, 991.

Andreassi (2010). Psychophysiology. Psychology Press. Available online at: https:// www.taylorfrancis.com/books/9780203880340. doi: 10.4324/9780203880340

Bauer, L. O., and Manning, K. J. (2016). Challenges in the detection of working memory and attention decrements among overweight adolescent girls. Neuropsychobiology 73, 43-51. doi: 10.1159/000442670

Blechert, J., Ansorge, U., Beckmann, S., and Tuschen-Caffier, B. (2011a). The undue influence of shape and weight on self-evaluation in anorexia nervosa, bulimia nervosa and restrained eaters: a combined ERP and behavioral study. Psychol Med. 41, 185-194. doi: 10.1017/S0033291710000395

Blechert, J., Feige, B., Joos, A., Zeeck, A., and Tuschen-Caffier, B. (2011b). Electrocortical processing of food and emotional pictures in anorexia nervosa and bulimia nervosa. Psychosom Med. 73, 415-421. doi: 10.1097/PSY.0b013e318211b871

Blume, M., Schmidt, R., and Hilbert, A. (2019). Abnormalities in the EEG power spectrum in bulimia nervosa, binge-eating disorder, and obesity: a systematic review. Eur Eat Disord Rev. 27, 124-136. doi: 10.1002/erv.2654

Brooks, S. J., Rask-Andersen, M., Benedict, C., and Schiöth, H. B. (2012). A debate on current eating disorder diagnoses in light of neurobiological findings: is it time for a spectrum model? BMC Psychiatry 12:76. doi: 10.1186/1471-244X-12-76

Brown, S. B. R. E., van Steenbergen, H., Band, G. P. H., de Rover, M., and Nieuwenhuis, S. (2012). Functional significance of the emotion-related late positive potential. Front Hum Neurosci. 6, 1-12. doi: 10.3389/fnhum.2012.00033

Chami, R., Cardi, V., Lautarescu, A., Mallorquí-Bagu,é N., and McLoughlin, G. (2019). Neural responses to food stimuli among individuals with eating and weight disorders: a systematic review of event-related potentials. Int Rev Psychiatry 31, 318-331. doi: 10.1080/09540261.2019.162 2515

Chami, R., Treasure, J., Cardi, V., Lozano-Madrid, M., Eichin, K. N., McLoughlin, G., et al. (2020). Exploring changes in event-related potentials after a feasibility trial of inhibitory training for bulimia nervosa and binge eating disorder. Front Psychol. 11, 1-12. doi: 10.3389/fpsyg.2020.01056

Cohen, M. X. (2014). Analyzing Neural Time Series Data: Theory and Practice. Cambridge, MA: The MIT Press.

Crowley, K. E., and Colrain, I. M. (2004). A review of the evidence for P2 being an independent component process: age, sleep and modality. Clin. Neurophysiol. 115, 732-744. doi: 10.1016/j.clinph.2003.11.021

daSilva, E. B., Crager, K., and Puce, A. (2016). On dissociating the neural time course of the processing of positive emotions. Neuropsychologia 83, 123-137. doi: 10.1016/j.neuropsychologia.2015.12.001

David, I. A., Volchan, E., Vila, J., Keil, A., de Oliveira, L., Faria-Júnior, A. J. P., et al. (2011). Stroop matching task: role of feature selection and temporal modulation. Exp. Brain Res. 208, 595-605. doi: 10.1007/s00221-010-2507-9

Delgado-Rodríguez, R., Hernández-Rivero, I., Fernández-Santaella, M. C., Vila, J., Guerra, P., and Miccoli, L. (2019). Neural processing of food and erotic cues in bulimia nervosa. Psychosom Med. 81, 527-535. doi: 10.1097/PSY.0000000000000704

Donkers, F. C. L., and van Boxtel, G. J. M. (2004). The N2 in go/no-go tasks reflects conflict monitoring not response inhibition. Brain Cogn. 56, 165-176. doi: 10.1016/j.bandc.2004.04.005

Fairburn, C. G., and Harrison, P. J. (2003). Eating disorders. Lancet 361, 407-416. doi: 10.1016/S0140-6736(03)12378-1

Farkas, A. H., Oliver, K. I., and Sabatinelli, D. (2020). Emotional and featurebased modulation of the early posterior negativity. Psychophysiology 57, 1-10. doi: 10.1111 /psyp.13484

Folstein, J. R., and Van Petten, C. (2007). Influence of cognitive control and mismatch on the N2 component of the ERP: a review. Psychophysiology 45, 152-170. doi: 10.1111/j.1469-8986.2007.00602.x

Gehring, W. J., Goss, B., Coles, M. G. H., Meyer, D. E., and Donchin, E. (2018). The error-related negativity. Perspect. Psychol. Sci. 13, 200-204. doi: 10.1177/1745691617715310

Gehring, W. J., Liu, Y., Orr, J. M., and Carp, J. (2011). The Error-Related Negativity $(E R N / \mathrm{Ne})$. New York, NY: Oxford University Press.

Hajcak, G., and Foti, D. (2020). Significance?... Significance! Empirical, methodological, and theoretical connections between the late positive potential and P300 as neural responses to stimulus significance: an integrative review. Psychophysiology 57, 1-15. doi: 10.1111/psyp.13570 
Hajcak, G., MacNamara, A., and Olvet, D. M. (2010). Event-related potentials, emotion, and emotion regulation: an integrative review. Dev. Neuropsychol. 35, 129-155. doi: 10.1080/87565640903526504

Heidlmayr, K., Kihlstedt, M., and Isel, F. (2020). A review on the electroencephalography markers of Stroop executive control processes. Brain Cogn. 146:105637. doi: 10.1016/j.bandc.2020. 105637

Herrmann, C. S., Rach, S., Vosskuhl, J., and Strüber, D. (2014). Time-frequency analysis of event-related potentials: a brief tutorial. Brain Topogr. 27, 438-450. doi: 10.1007/s10548-013-0327-5

Herzog, R., Álvarez-Pasquin, M. J., Díaz, C., Del Barrio, J. L., Estrada, J. M., and Gil, Á. (2013). Are healthcare workers' intentions to vaccinate related to their knowledge, beliefs and attitudes? a systematic review. BMC Public Health 13:154. doi: 10.1186/1471-2458-13-154

Hillyard, S. A., Vogel, E. K., and Luck, S. J. (1998). Sensory gain control (amplification) as a mechanism of selective attention: electrophysiological and neuroimaging evidence. Philos. Trans. R Soc. London Ser. B Biol. Sci. 353, 1257-1270. doi: 10.1098/rstb.1998.0281

Hume, D. J., Howells, F. M., Karpul, D., Rauch, H. G. L. G.L., Kroff, J., and Lambert, E. V. (2015b). Cognitive control over visual food cue saliency is greater in reduced-overweight/obese but not in weight relapsed women: an EEG study. Eat Behav. 19, 76-80. doi: 10.1016/j.eatbeh.2015.06.013

Hume, D. J., Howells, F. M., Rauch, H. G. L., Kroff, J., and Lambert, E. V. (2015a). Electrophysiological indices of visual food cue-reactivity. Differences in obese, overweight and normal weight women. Appetite 85, 126-137. doi: 10.1016/j.appet.2014.11.012

Imperatori, C., Fabbricatore, M., Farina, B., Innamorati, M., Quintiliani, M. I., Lamis, D. A., et al. (2015). Alterations of EEG functional connectivity in resting state obese and overweight patients with binge eating disorder: a preliminary report. Neurosci. Lett. 607, 120-124. doi: 10.1016/j.neulet.2015. 09.026

Insel, T., Cuthbert, B., Garvey, M., Heinssen, R., Pine, D. S., Quinn, K., et al. (2010). Research Domain Criteria (RDoC): toward a new classification framework for research on mental disorders. Am. J. Psychiatry 167, 748-751. doi: 10.1176/appi.ajp.2010.09091379

Jansen, A. (2016). Eating disorders need more experimental psychopathology. Behav. Res. Ther. 86, 2-10. doi: 10.1016/j.brat.2016.08.004

Jáuregui-Lobera, I. (2012). Electroencephalography in eating disorders. Neuropsychiatr. Dis. Treat. 8, 1-11. doi: 10.2147/NDT.S27302

Johnston, V. S., Miller, D. R., and Burleson, M. H. (1986). Multiple P3s to emotional stimuli and their theoretical significance. Psychophysiology 23, 684-694. doi: 10.1111/j.1469-8986.1986.tb00694.x

Jones, B. P., Duncan, C. C., Brouwers, P., and Mirsky, A. F. (1991). Cognition in eating disorders. J. Clin. Exp. Neuropsychol. 13, 711-728. doi: 10.1080/01688639108401085

Junghofer, M., Bradley, M. M., Elbert, T. R., and Lang, P. J. (2001). Fleeting images: a new look at early emotion discrimination. Psychophysiology 38, 175-178. doi: 10.1111/1469-8986.3820175

Kaisari, P., Dourish, C. T., and Higgs, S. (2017). Attention deficit hyperactivity disorder (adhd) and disordered eating behaviour: a systematic review and a framework for future research. Clin. Psychol. Rev. 53, 109-121. doi: 10.1016/j.cpr.2017.03.002

Kappenman, E. S., and Luck, S. J. (eds) (2011). The Oxford Handbook of EventRelated Potential Components. New York, NY: Oxford University Press.

Kessler, R. M., Hutson, P. H., Herman, B. K., and Potenza, M. N. (2016). The neurobiological basis of binge-eating disorder. Neurosci. Biobehav. Rev. 63, 223-238. doi: 10.1016/j.neubiorev.2016.01.013

Kim, D.-W., and Im, C.-H. (2018). EEG spectral analysis. Computational EEG Analysis 2018, 35-53. doi: 10.1007/978-981-13-0908-3_3

Klimesch, W. (1999). EEG alpha and theta oscillations reflect cognitive and memory performance: a review and analysis. Brain Res. Rev. 29, 169-195. doi: 10.1016/S0165-0173(98)00056-3

Krug, I., Pinheiro, A. P., Bulik, C., Jiménez-Murcia, S., Granero, R., Penelo, E., et al. (2009). Lifetime substance abuse, family history of alcohol abuse/dependence and novelty seeking in eating disorders: comparison study of eating disorder subgroups. Psychiatry Clin Neurosci. 63, 82-87. doi: 10.1111/j.1440-1819.2008.01908.x
Kuehnpast, N., Gramann, K., Pollatos, O., Kuhnpast, N., Gramann, K., Pollatos, O., et al. (2012). Electrophysiologic evidence for multilevel deficits in emotional face processing in patients with bulimia nervosa. Psychosom. Med. 74, 736-744. doi: 10.1097/PSY.0b013e31825ca15a

Kułakowska, D., Biernacka, K., Wilkos, E., Rybakowski, F., and KucharskaPietura, K. (2014). [Neurocognitive and social cognition deficits in patients with anorexia nervosa]. Psychiatr. Pol. 48, 465-475.

Kutas, M., and Federmeier, K. D. (2011). Thirty years and counting: finding meaning in the N400 Component of the Event-Related Brain Potential (ERP). Annu. Rev. Psychol. 62, 621-647. doi: 10.1146/annurev.psych.093008. 131123

Leehr, E. J., Schag, K., Brinkmann, A., Ehlis, A.-C., Fallgatter, A. J., Zipfel, S., et al. (2016). Alleged approach-avoidance conflict for food stimuli in binge eating disorder. PLoS ONE 11:e0152271. doi: 10.1371/journal.pone.0152271

Leehr, E. J., Schag, K., Dresler, T., Grosse-Wentrup, M., Hautzinger, M., Fallgatter, A. J., et al. (2018). Food specific inhibitory control under negative mood in binge-eating disorder: evidence from a multimethod approach. Int. J. Eat Disord. 51, 112-123. doi: 10.1002/eat.22818

Lemos, T. C., Almo, A., Campagnoli, R. R., Pereira, M. G., Oliveira, L., Volchan, E., et al. (2020). A red code triggers an unintended approach motivation toward sweet ultra-processed foods: possible implications for front-of-pack labels. Food Qual. Prefer. 79:103784. doi: 10.1016/j.foodqual.2019.103784

Léonard, T., Pepinà, C., Bond, A., and Treasure, J. (1998). Assessment of test-meal induced autonomic arousal in anorexic, bulimic and control females. Eur. Eat Disord. Rev. 6, 188-200. doi: 10.1002/(SICI)1099-0968(199809)6:3<188::AIDERV227>3.0.CO;2-G

Littel, M., Euser, A. S., Munaf,ò M. R., and Franken, I. H. A. (2012). Electrophysiological indices of biased cognitive processing of substancerelated cues: a meta-analysis. Neurosci. Biobehav. Rev. 36, 1803-1816. doi: 10.1016/j.neubiorev.2012.05.001

Lobo, I., David, I. A., Figueira, I., Campagnoli, R. R., Volchan, E., Pereira, M. G., et al. (2014). Brain reactivity to unpleasant stimuli is associated with severity of posttraumatic stress symptoms. Biol. Psychol. 103, 233-241. doi: 10.1016/j.biopsycho.2014.09.002

Luck, S. J. (2014). An Introduction to the Event-Related Potential Technique. Second Edition. Cambridge, MA: The MIT Press.

Mai, S., Gramann, K., Herbert, B. M., Friederich, H.-C., Warschburger, P., and Pollatos, O. (2015). Electrophysiological evidence for an attentional bias in processing body stimuli in bulimia nervosa. Biol. Psychol. 108, 105-114. doi: 10.1016/j.biopsycho.2015.03.013

Makeig, S., Debener, S., Onton, J., and Delorme, A. (2004). Mining event-related brain dynamics. Trends Cogn. Sci. 8, 204-210. doi: 10.1016/j.tics.2004.03.008

McKay, S. E., Humphries, L. L., Allen, M. E., and Clawson, D. R. (1986). Neuropsychological test performance of bulimic patients. Int. J. Neurosci. 30, 73-80. doi: 10.3109/00207458608985657

Merlotti, E., Mucci, A., Volpe, U., Montefusco, V., Monteleone, P., Bucci, P., et al. (2013). Impulsiveness in patients with bulimia nervosa: electrophysiological evidence of reduced inhibitory control. Neuropsychobiology 68, 116-123. doi: 10.1159/000352016

Moher, D., Liberati, A., Tetzlaff, J., and Altman, D. G., P. R. I. S. M. A., Group (2009). Preferred reporting items for systematic reviews and meta-analyses: the PRISMA statement. Ann. Intern. Med. 151, 264-269. doi: 10.7326/0003-4819-151-4-200908180-00135

Monica, D., Paulo, M., Appolinário, J. C., Freitas, S. R., de, Coutinho, G., Santos, C., et al. (2010). Assessment of executive functions in obese individuals with binge eating disorder. Rev Bras Psiquiatr. 32, 381-388. doi: 10.1590/S1516-44462010000400011

Niedermeyer, E., and da Silva, F. H. L. (2004). Electroencephalography: Basic Principles, Clinical Applications, and Related Fields. Vol. 1. Philadelphia, PA: Lippincott Williams and Wilkins. 1309.

Otagaki, Y., Tohoda, Y., Osada, M., Horiguchi, J., and Yamawaki, S. (1998). Prolonged P300 latency in eating disorders. Neuropsychobiology 37, 5-9. doi: $10.1159 / 000026470$

Pacheco, L. B., Figueira, J. S., Pereira, M. G., Oliveira, L., and David, I. A. (2020). Controlling unpleasant thoughts: adjustments of cognitive control based on previous-trial load in a working memory task. Front. Hum. Neurosci. 13, 1-12. doi: 10.3389/fnhum.2019.00469 
Pearson, C. M., Lavender, J. M., Cao, L., Wonderlich, S. A., Crosby, R. D., Engel, S. G., et al. (2017). Associations of borderline personality disorder traits with stressful events and emotional reactivity in women with bulimia nervosa. J. Abnorm. Psychol. 126, 531-539. doi: 10.1037/abn00 00225

Polich, J. (2007). Updating P300: An integrative theory of P3a and P3b. Clin Neurophysiol. 118, 2128-2148. doi: 10.1016/j.clinph.2007. 04.019

Polich, J. (2011). Neuropsychology of P300. Oxford University Press. Available online at: http://oxfordhandbooks.com/view/10.1093/oxfordhb/ 9780195374148.001.0001/oxfordhb-9780195374148-e-007

Riesel, A., Klawohn, J., Kathmann, N., and Endrass, T. (2017). Conflict monitoring and adaptation as reflected by $\mathrm{N} 2$ amplitude in obsessive-compulsive disorder. Psychol. Med. 47, 1379-1388. doi: 10.1017/S0033291716003597

Rodriguez, G., Babiloni, C., Brugnolo, A., Del Percio, C., Cerro, F., Gabrielli, F., et al. (2007). Cortical sources of awake scalp EEG in eating disorders. Clin Neurophysiol. 118, 1213-1222. doi: 10.1016/j.clinph.2007.02.022

Schienle, A., Schäfer, A., Hermann, A., and Vaitl, D. (2009). Binge-eating disorder: reward sensitivity and brain activation to images of food. Biol. Psychiatry 65, 654-661. doi: 10.1016/j.biopsych.2008.09.028

Schienle, A., Scharmuller, W., and Schwab, D. (2017). Processing of visual food cues during bitter taste perception in female patients with binge-eating symptoms: a cross-modal ERP study. Clin. Neurophysiol. 128, 2184-2190. doi: 10.1016/j.clinph.2017.08.017

Schupp, H. T., Junghöfer, M., Weike, A. I., and Hamm, A. O. (2003a). Attention and emotion: an ERP analysis of facilitated emotional stimulus processing. Neuroreport 14, 1107-1110. doi: 10.1097/00001756-20030611000002

Schupp, H. T., Markus, J., Weike, A. I., and Hamm, A. O. (2003b). Emotional facilitation of sensory processing in the visual cortex. Psychol. Sci. 14, 7-13. doi: $10.1111 / 1467-9280.01411$

Schupp, H. T., Stockburger, J., Codispoti, M., Junghofer, M., Weike, A. I., and Hamm, A. O. (2007). Selective visual attention to emotion. J. Neurosci. 27, 1082-1089. doi: 10.1523/JNEUROSCI.3223-06.2007

Startup, H., Lavender, A., Oldershaw, A., Stott, R., Tchanturia, K., Treasure, J., et al. (2013). Worry and rumination in anorexia nervosa. Behav. Cogn. Psychother. 41, 301-316. doi: 10.1017/S1352465812000847

Steinglass, J. E., Berner, L. A., and Attia, E. (2019). Cognitive neuroscience of eating disorders. Psychiatr. Clin. North Am. 42, 75-91. doi: 10.1016/j.psc.2018.10.008

Stojek, M., Shank, L. M., Vannucci, A., Bongiorno, D. M., Nelson, E. E., Waters, A. J., et al. (2018). A. systematic review of attentional biases in disorders involving binge eating. Appetite 123, 367-389. doi: 10.1016/j.appet.2018.01.019

Sutton, S., Braren, M., Zubin, J., and John, E. R. (1965). Evoked-potential correlates of stimulus uncertainty. Science (80-) 150, 1187-1188. doi: $10.1126 /$ science. 150.3700 .1187

Svaldi, J., Tuschen-Caffier, B., Peyk, P., and Blechert, J. (2010). Information processing of food pictures in binge eating disorder. Appetite 55, 685-694. doi: 10.1016/j.appet.2010.10.002
Tammela, L. I., Pääkkönen, A., Karhunen, L. J., Karhu, J., Uusitupa, M. I. J., and Kuikka, J. T. (2010). Brain electrical activity during food presentation in obese binge-eating women. Clin. Physiol. Funct. Imaging 30, 135-140. doi: 10.1111/j.1475-097X.2009.00916.x

Tchanturia, K., Morris, R. G., Anderluh, M. B., Collier, D. A., Nikolaou, V., and Treasure, J. (2004). Set shifting in anorexia nervosa: an examination before and after weight gain, in full recovery and relationship to childhood and adult OCPD traits. J. Psychiatr. Res. 38, 545-552. doi: 10.1016/j.jpsychires.2004.03.001

Tchanturia, K., Morris, R. G., Surguladze, S., and Treasure, J. (2002). An examination of perceptual and cognitive set shifting tasks in acute anorexia nervosa and following recovery. Eat Weight Disord. 7, 312-315. doi: $10.1007 / \mathrm{BF} 03324978$

U. S. Department of Health and Human Services, National Institutes of Health NI of MH. (2020). Strategic Plan for Research. Available online at: https://www. nimh.nih.gov/about/strategic-planning-reports/2020_nimh_strategic_plan_ 508_160162.pdf

Verkes, R. J., Pijl, H., Meinders, A. E., and Van Kempen, G. M. J. (1996). Borderline personality, impulsiveness, and platelet monoamine measures in bulimia nervosa and recurrent suicidal behavior. Biol. Psychiatry 40, 173-180. doi: 10.1016/0006-3223(95)00384-3

Vogel, E. K., and Luck, S. J. (2000). The visual N1 component as an index of a discrimination process. Psychophysiology 37, 190-203. doi: 10.1111/1469-8986.3720190

Wang, L., Gu, Y., Zhao, G., and Chen, A. (2020). Error-related negativity and error awareness in a Go/No-go task. Sci Rep. 10:4026 doi: 10.1038/s41598-020-60693-0

Wolz, I., Fagundo, A. B., Treasure, J., and Fernandez-Aranda, F. (2015). The processing of food stimuli in abnormal eating: a systematic review of electrophysiology. Eur Eat Disord. Rev. 23, 251-261. doi: 10.1002/erv.2366

Wolz, I., Sauvaget, A., Granero, R., Mestre-Bach, G., Bano, M., Martin-Romera, V., et al. (2017). Subjective craving and event-related brain response to olfactory and visual chocolate cues in binge-eating and healthy individuals. Sci. Rep. 7:41736. doi: 10.1038/srep41736

Wronka, E., Kaiser, J., and Coenen, A. M. L. (2008). The auditory P3 from passive and active three-stimulus oddball paradigm. Acta Neurobiol. Exp. 68, 362-372.

Conflict of Interest: The authors declare that the research was conducted in the absence of any commercial or financial relationships that could be construed as a potential conflict of interest.

Copyright (C) 2021 Hiluy, David, Daquer, Duchesne, Volchan and Appolinario. This is an open-access article distributed under the terms of the Creative Commons Attribution License (CC BY). The use, distribution or reproduction in other forums is permitted, provided the original author(s) and the copyright owner(s) are credited and that the original publication in this journal is cited, in accordance with accepted academic practice. No use, distribution or reproduction is permitted which does not comply with these terms. 